\title{
Conhecimento de pescadores tradicionais sobre a dinâmica espaço-temporal de recursos naturais na Chapada Diamantina, Bahia
}

\author{
Flávia de Barros Prado Moura ${ }^{1,3}$ \& José Geraldo Wanderley Marques ${ }^{2}$ \\ Biota Neotropica v7 (n3) - http://www.biotaneotropica.org.br/v7n3/pt/abstract?article+bn01807032007 \\ Recebido em 18/10/2006 \\ Versão reformulada recebida 31/08/07 \\ Publicado em 17/09/2007 \\ ${ }^{1}$ Museu de História Natural, Universidade Federal de Alagoas, \\ Rua Aristeu de Andrade, 452, Farol, CEP 57051-090, Maceió, AL, Brasil \\ ${ }^{2}$ Departamento de Biologia, Universidade Estadual de Feira de Santana - UEFS, \\ Av. Universitária, s/n, Km 03, BR 116.Campus Universitário, \\ CEP 44031-460, Feira de Santana, BA, Brasil \\ ${ }^{3}$ Autor para correspondência: Flávia de Barros Prado Moura, \\ e-mail: flavia.moura@pesquisador.cnpq.br,http://www.ufal.br/ufal/
}

\begin{abstract}
Moura, F.B.P. \& Marques, J.G.W. The knowledge of traditional fishermen regarding the spatio-temporal dynamics of natural resources in the Chapada Diamantina region, state of Bahia. Biota Neotrop. Sep/ Dez 2007 vol. 7, no.3 http://www.biotaneotropica.org.br/v7n3/pt/abstract?article+bn01807032007. ISSN 16760603.

This paper examines the traditional ecological knowledge of a community of fishermen that live in the APA Marimbus-Iraquara (Conservation Unit). The study aimed at collecting information regarding mainly local perception about the spatial and seasonal distribution of natural resources. Data were collected using open and semi-structured interviews, field observation and guided tours. Also, zoological and botanical materials were collected. The study results indicate the existence of a broad local ecological knowledge about species and ecosystems, particularly in relation to fish species.

Keywords: conservation unit; traditional knowledge; ethnoecology.

Resumo

Moura, F.B.P. \& Marques, J.G.W. Conhecimento de pescadores tradicionais sobre a dinâmica espaçotemporal de recursos naturais na Chapada Diamantina, Bahia. Biota Neotrop. Sep/Dez 2007 vol. 7, no. 3 http://www.biotaneotropica.org.br/v7n3/pt/abstract?article+bn01807032007. ISSN 1676-0603.

O conhecimento ecológico tradicional de uma população de pescadores da APA de Marimbus-Iraquara, foi estudado visando obter informações relacionadas à percepção local sobre distribuição espacial e sazonal dos recursos naturais. Os dados foram obtidos por meio de entrevistas livres e semi-estruturadas, observações diretas, turnês guiadas e coletas de material zoológico. Os resultados sugerem a existência de um amplo conhecimento ecológico tradicional sobre as espécies e os ecossistemas locais, especialmente no que se refere à ictiofauna.

Palavras-chave: Chapada Diamantina; conhecimento tradicional; etnoecologia.
\end{abstract}




\section{Introdução}

O conhecimento ecológico/biológico sob domínio intelectual de populações tradicionais tem sido estudado com diversas abordagens, revelando sistemas de classificação de animais e plantas (Jensen 1985, Berlin 1992, Mourão \& Nordi 2002, Montenegro 2002), estratégias de coleta/captura de espécimes (Marques 1991, 1995, Lévi-Strauss 1987, Hanazaki 2003, Begossi 2006, Souto 2007), medicina/farmacologia (Elisabetsky 1987, Figueredo et al. 1993, Silva 1997), astronomia (Ribeiro 1987), além de técnicas de uso e manejo de recursos naturais (Anderson \& Anderson 1983, Posey 1983, 1984, 1987). Muitos conhecimentos tradicionais têm sido usados para a elaboração de hipóteses testáveis, tanto nas pesquisas botânicas/farmacológicas (Cox \& Balick 1994), quanto nas zoológicas/ecológicas (Marques 1991).

Populações tradicionais possuem técnicas próprias de uso e manejo dos recursos naturais, através das quais interferem no processo de sucessão ecológica, promovem a regeneração de áreas degradadas, a ciclagem de nutrientes e o aumento da riqueza de espécies nos ecossistemas manejados (Posey 1983, 1984, Morin-Labatut \& Akatar 1992, Balée 1994). A consistência e a adequação do conhecimento tradicional ao manejo e à conservação local de recursos, levaram alguns pesquisadores a sugerir seu uso na definição de propostas oficiais de manejo e conservação (Morin-Labatut \& Akatar 1992), ou para gerar desenvolvimento com sustentabilidade ecológica e cultural (Posey 1984, Overal \& Posey 1996).

Na Chapada Diamantina, por exemplo, ainda sobrevivem dezenas de populações humanas relativamente isoladas, vivendo da agricultura de subsistência e de atividades extrativistas como a pesca, a caça, a coleta de mel e a retirada de madeiras. O conhecimento local, assim como as necessidades econômicas e culturais das populações tradicionais, têm sido desconsiderados na formulação de políticas de desenvolvimento para a região, que privilegiam o turismo de massa, gerando, como conseqüência, impactos negativos sobre o ambiente e a cultura.

O objetivo deste trabalho foi descrever o conhecimento ecológico local sobre a dinâmica espacial e sazonal de espécies e dos ecossistemas que compõem uma área úmida, conhecida como marimbus. A área, situada dentro de uma Unidade de Conservação (APA de Marimbus - Iraquara) na Chapada Diamantina, é utilizada para a realização de atividades extrativistas de subsistência por pescadores tradicionais que vivem num povoado denominado de Remanso. Também foram investigadas possíveis similaridades entre o conhecimento local e a literatura científica disponível, particularmente sobre estilos reprodutivos de peixes (Balon 1975), como forma de reforçar o aspecto de complementaridade entre estas duas formas de conhecimento.

\section{Metodologia}

\section{1. Área de estudo e população}

A Chapada Diamantina é um extenso planalto $\left(38.000 \mathrm{~km}^{2}\right)$, que corresponde a 15\% do Estado da Bahia (Funch 1997). Constitui-se de um mosaico paisagístico que apresenta variações fisionômicas a distâncias muito curtas: sobre solos de fertilidade média e alta desenvolvem-se florestas e caatingas, seguindo principalmente os níveis de precipitação e profundidade do solo; sobre solos pobres e ácidos desenvolvem-se diversos tipos de cerrado; as regiões de planícies periodicamente alagadas, de solos aluviais, apresentam cobertura constituída por vegetação hidrófila; nas margens dos rios desenvolvem-se matas ciliares e ripárias.

Em 1985, o Decreto n 91655 criou o Parque Nacional da Chapada Diamantina, colocando parte da Chapada sob proteção da Legislação
Federal. A Área de Proteção Ambiental de Marimbus-Iraquara foi criada pelo Decreto Estadual $n^{\circ} 2216$, em 1993, visando ampliar o limite da área protegida (Urplan 1996). A APA abrange $1.254 \mathrm{~km}^{2}$, com trechos de cinco municípios, três dos quais - Lençóis, Andaraí e Palmeiras - também têm parte de suas terras localizadas no Parque Nacional.

Na porção da APA a leste do Parque Nacional, a maior precipitação permite a ocorrência de matas mesófilas cujo estrato superior atinge cerca de 15 a 20 metros de altura. Nesta porção, devido à confluência de rios em uma zona de relevo muito plano, uma grande área marginal fica sujeita a inundações periódicas (Lima \& Nolasco 1997). As áreas periodicamente alagáveis, cobertas por vegetação hidrófila, principalmente das famílias Araceae e Cyperaceae, são denominadas localmente de marimbus. Matas, rios, lagoas e marimbus caracterizam e distinguem essas terras, onde está situado o povoado do Remanso, dando suporte a uma população de aproximadamente 206 pessoas que praticam agricultura de subsistência e pescam nos rios e lagoas.

A escolha deste grupo humano deve-se aos seguintes aspectos: a) a riqueza de espécies e a singularidade dos ecossistemas por eles utilizados (matas, rios, lagoas e zonas alagáveis, que excetuam suas terras da paisagem predominante na Chapada Diamantina, e conferem à área uma elevada riqueza de espécies própria das zonas ecotonais); b) o seu isolamento relativo (o acesso ao povoado ainda se faz por uma precária estrada não pavimentada, praticamente intransitável na estação das chuvas, vivendo a população sem acesso a serviços essenciais); c) maior vulnerabilidade aos impactos ambientais aos quais tanto o grupo humano quanto os ecossistemas estão sujeitos (provocados pelo turismo desordenado, feito em uma APA, e não em um Parque Nacional, como ocorre em outras áreas da Chapada); d) a escassez de dados relacionados à fauna da área dos marimbus; e e) habilidade com a qual a população humana interage localmente com recursos naturais, principalmente com os recursos aquáticos, sendo reconhecidos na região como pescadores habilidosos.

\section{Coleta de dados}

Nos três meses iniciais de trabalho foram visitadas 20 residências do povoado $(60 \%)$ para entrevistas iniciais. Foi utilizada nesta etapa a "metodologia geradora de dados"(Posey 1987), que se baseia em perguntas abertas, visando obter o máximo de informações e categorias locais. Nesta etapa foram identificados cinco especialistas ou consultores culturais, entre pessoas que são reconhecidas pela população e se auto-reconhecem como os principais detentores de conhecimentos sobre os recursos locais. Com os consultores culturais, utilizando-se terminologias e conceitos locais já identificados na etapa inicial, foram realizadas entrevistas temáticas. As entrevistas tiveram duração variando de 15 a 60 minutos. Ao todo foram realizadas de duas a cinco entrevistas com cada consultor. As entrevistas foram gravadas e transcritas em caderno de campo.

O modelo da união das diversas competências (Hays 1976, Werner \& Fenton, 1973) foi utilizado para a sistematização dos dados. Para verificar a consistência e validade das informações obtidas foram utilizadas duas técnicas de controle: na primeira recorreu-se a entrevistas repetidas em situações sincrônicas e diacrônicas (Marques 1991), nas quais perguntas eram feitas a pessoas diferentes em tempos muito próximos, ou a mesma pessoa em períodos distintos; na segunda utilizou-se a técnica de grupos focais (Oliveira \& Werba 1999) adaptada à circunstância de formação espontânea de grupo, ou seja, aproveitando-se da existência de grupos formados para desempenho de atividades comunitárias rotineiras. A estes grupos submetiam-se perguntas cujas respostas haviam sido anteriormente discrepantes entre pescadores distintos, incentivando-se, então, o debate informal, no qual o pesquisador assumia o papel de mediador. 
Para observações de campo e coleta de dados sobre os locais onde estão localizados os recursos, usou-se a técnica de"turnês guiadas"pela área de estudo (Spradley \& McCurdy 1972). Complementarmente, foi solicitada a um dos consultores culturais a elaboração de um"mapa"da área estudada, como forma de verificar a percepção local sobre o ecozoneamento. O modelo de "mapa mental" tem sido empregado amplamente na representação de lugar, apoiadas em teorias da Psicologia, Cartografia e Geografia (Archela et al. 2004). O “mapa” obtido foi inicialmente copiado em papel vegetal e, em seguida escaneado e ilustrado com auxílio de computação gráfica.

As espécies coletadas $(n=18)$ foram preparadas segundo as técnicas usuais para material zoológico e inseridas nas coleções científicas da Universidade Estadual de Feira de Santana e da Universidade Federal de São Carlos, onde foram identificadas. As demais espécies (mamíferos, aves e plantas) foram identificadas através de pistas taxonômicas fornecidas pela população local, material de coleção científica coletado na área, disponível na Universidade Estadual de Feira de Santana e consulta a bibliografia (Urplan 1996). Duas espécies de peixes não foram coletadas. De acordo com a descrição morfológica e etológica feita pelos pescadores, eles podem corresponder respectivamente a Brycon lundi (Reinhardt, 1877) e Conorhynchus conirostris (Valenciennes, 1840), com ocorrências registradas para a bacia (Santos 2003).

\section{Resultados e Discussão}

\section{Percepção espacial e "mapa mental"}

A área onde está situado o povoado do Remanso caracteriza-se pela presença de uma zona central -os marimbus - periodicamente alagada e coberta por vegetação hidrófila, a partir da qual, centrifugamente, rios, lagoas e matas se sucedem. A partir do "mapa mental" (Figura 1), pode-se identificar as zonas com grande nível de detalhamento. Entre os ecossistemas aquáticos, distinguem-se os rios (águas correntes), as lagoas (águas paradas) e os marimbus (cujos solos só se apresentam cobertos por água no período das enchentes). O "mapa" mostra no rio, ecozonas distintas, tanto de origem natural - "veio e corrida de rio" - que correspondem respectivamente a áreas de menor e maior correnteza, quanto antrópica - "canal e rio entupido" - o primeiro, cavado pelo homem, em meio aos marimbus e o segundo, fruto do assoreamento do rio.

Conhecer bem os ecossistemas locais, assim como os fatores ambientais que influenciam a distribuição e a abundância dos recursos, é fundamental na definição das estratégias de pesca, caça e coleta, que implicam escalas (espaciais e temporais) e instrumentos. Os pescadores consultados mostraram conhecer, com detalhes, a distribuição

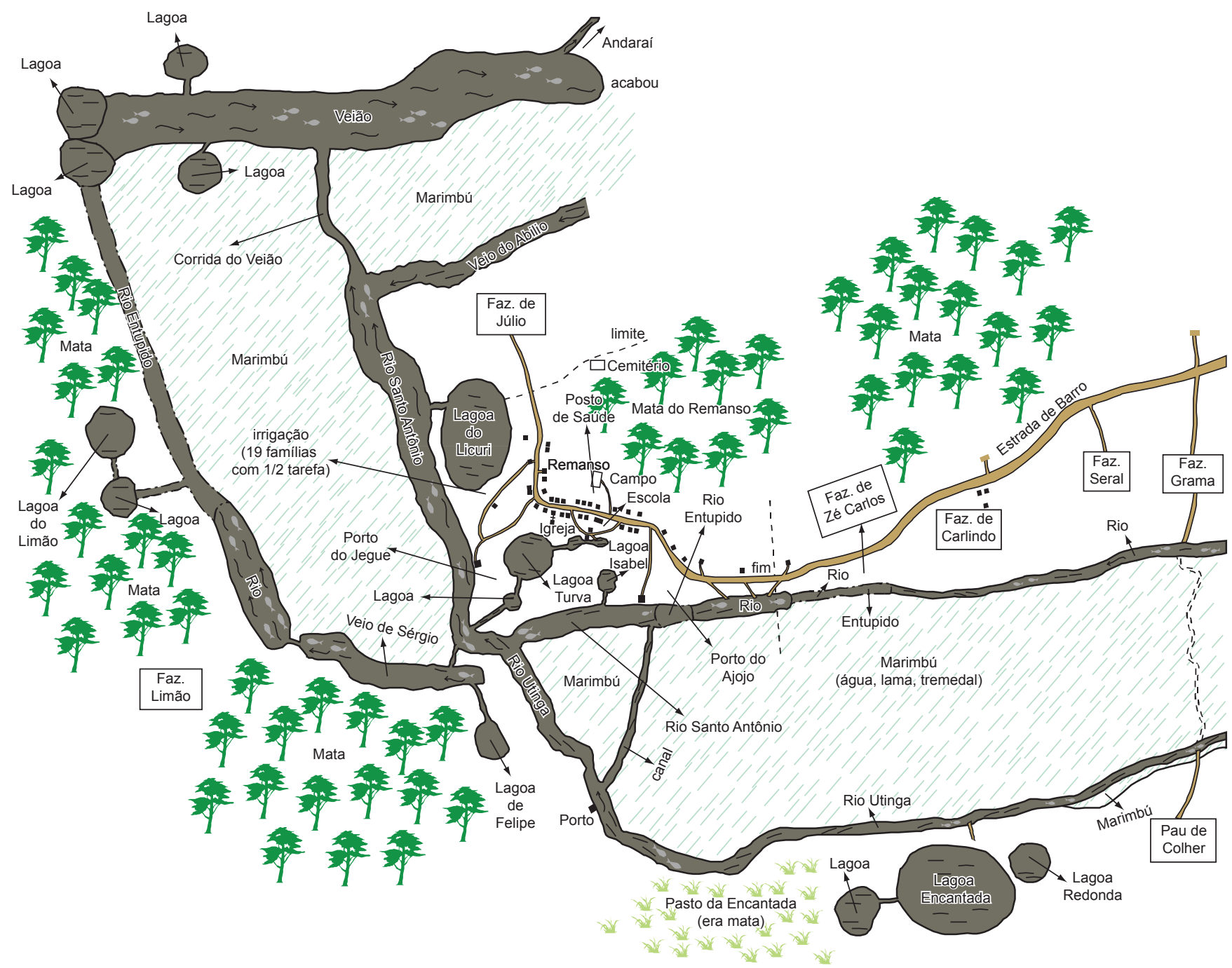

Figura 1. "mapa mental" da área de estudo, mostrando diferentes ambientes reconhecidos pelos pescadores.

Figure 1. "mental map" of the study region identifying different environment patterns as perceived by the fishermen. 
espacial dos peixes (Tabela 1), pelo menos no que se refere às vinte espécies de valor utilitário, as quais são classificadas como: "peixes do rio" (o pira, o piau, o uiú, o peixe-cachorro, o cumbá, a crumatá, a sabarona e a traíra cabeça-fina; "peixes que preferem a lagoa mas também andam no rio" (o apanhari, a traíra cabeça-de-lama, o jundiá, o corró-branco e o corró-preto); "peixes tanto do rio quanto da lagoa" (referido-se à maior plasticidade na ocupação de ambientes, exibida por peixes como: a piranha, o tucunaré, as piabas, o peixe-cobra, a matrinchã e o carí). Nenhum peixe foi reconhecido como tendo sua distribuição restrita à lagoa. $\mathrm{O}$ conhecimento local com relação à distribuição espacial dos peixes, tanto nas lagoas, quanto nos rios, mostrou-se consistente com a literatura disponível (Von Ihering 1928, Nomura 1976, Bittencourt \& Cox-Fernandes 1990, Agostinho et al. 1995, Rantin et al. 1993).

A sofisticação do conhecimento local pode ser verificada, entre outros aspectos, pelo detalhamento com o qual os informantes distinguem, do ponto de vista ecológico, espécies do mesmo gênero reconhecendo, tanto a preferência da chamada traíra-cabeça-de-lama (H. malabaricus) por águas paradas de lagoas, quanto a distribuição restrita de traíra-cabeça-fina/guelra-de-veludo (H. cf. lacerdae $)$ em águas correntes de rios. Rantin et al. (1993) afirma que H. malabaricus é amplamente distribuída em ambientes lênticos (lagos e lagoas), podendo habitar, inclusive, águas estagnadas, enquanto $H$. lacerdae habita exclusivamente águas bem oxigenadas.

Além das informações sobre a distribuição espacial dos peixes, através do depoimento de pescadores mais velhos, foi possível obter dados sobre mudanças ambientais causadas pela ação antrópica nos últimos anos, tal como o assoreamento dos rios e a introdução de espécies exóticas. Esta última ação teria alterado a composição da ictiofauna e, provavelmente, a densidade de algumas populações. $\mathrm{O}$ tucunaré teria"colocado muito peixe pra correr"ou"metido medo"nas espécies nativas. Os dados da literatura suportam essas afirmações das populações nativas, uma vez que se trata de uma espécie piscívora e agressiva (Jempsen et al. 1997).

O tucunaré, embora não seja uma espécie nativa, é aparentemente o peixe sobre o qual o conhecimento local se mostrou mais elaborado. Isso pode ocorrer porque ele foi introduzido há muito tempo (cerca de 30 anos segundo as informações locais) e hoje apresenta a maior importância pesqueira. Destacam-se os conhecimentos sobre a quantidade de ovos e tempo de incubação, além dos procedimentos de preparação do ninho e de covas ou "barrocas" no fundo do rio para abrigar filhotes recém-nascidos. Segundo as informações obtidas, o tempo de incubação dos ovos é de cerca de cinco dias. Afirmaram, ainda, que para cada ninho são construídas cinco a seis barrocas no fundo do rio. Segundo as informações locais, esse procedimento confere mais segurança contra predadores ou contra possíveis flutuações no nível das águas, uma vez que as covas encontram-se próximas às margens que eventualmente podem secar. As informações disponíveis na literatura ictiológica sobre substrato selecionado (Santos 1987), guarda do ninho pelo casal (Lowe-McConell 1987) e tempo dedicado ao cuidado com a prole (Junk 1983), em relação aos ciclídeos, estão de acordo com as informações fornecidas pelos pescadores (Tabela 2).

\section{Percepção local sobre as variações sazonais}

Ao longo de um ciclo anual, com duas estações bem definidas, fenômenos bióticos relacionados à fauna e à flora estruturam-se de forma dinâmica. Esse dinamismo é percebido e descrito pelos entrevistados, que reconheceram uma estação fria e seca, denominada

Tabela 1. Peixes, correspondência taxonômica e preferência de habitat: A) peixes de rio; B) peixes que preferem lagoa, mas também andam no rio; C) peixes tanto do rio quanto de lagoa.

Table 1. Fish, their scientific names and habitat preference: A) river fish; B) fish that prefer ponds but that occasionally occur in rivers; C) fish that occur both in ponds and rivers.

\begin{tabular}{|c|c|c|c|c|}
\hline \multirow[t]{2}{*}{ Denominação local } & \multirow[t]{2}{*}{ Espécie } & \multicolumn{3}{|c|}{ Preferência de habitat } \\
\hline & & A & $\mathrm{B}$ & $\mathrm{C}$ \\
\hline Apanharí & Astronotus ocellatus (Cuvier, 1829). & - & $\mathrm{x}$ & - \\
\hline Cari & Hypostomus sp. & - & - & $\mathrm{x}$ \\
\hline Corró-preto & Geophagus brasiliensis (Quoy \& Gaimard, 1824). & - & $\mathrm{x}$ & - \\
\hline Corro-branco & Cichlasoma sanctifranciscense Kullander, 1983 & - & $\mathrm{x}$ & - \\
\hline Crumatá & Prochilodus affinis (Reinhardt, 1874). & $\mathrm{x}$ & - & - \\
\hline Cumbá & Parauchenipterus galeatus (Linnaeus, 1766). & $\mathrm{x}$ & - & - \\
\hline Jundiá & Rhamdia cf. quelen (Quoy \& Gaimard, 1824). & - & $\mathrm{x}$ & - \\
\hline Matrinchã* & Brycon lundii (Reinhardt,1877) (?) & - & - & $\mathrm{x}$ \\
\hline Peixe-cachorro & Acestrorhynchus cf. falcatus (Bloch, 1794) & $\mathrm{x}$ & - & - \\
\hline Peixe-cobra & Gymnotus carapo (Linnaeus, 1758). & - & - & $\mathrm{x}$ \\
\hline Piaba & Astyanax fasciatus (Cuvier, 1819). & - & - & $\mathrm{x}$ \\
\hline Piaba-dedo-de-moça & Astyanax gr bimaculatus (Reinhardt,1874) & - & - & $\mathrm{x}$ \\
\hline Piau & Leporinus bahiensis Steindachner 1875 & $\mathrm{x}$ & - & - \\
\hline Pirá* & Conorhynchus conirostris (Valenciennes, 1840) (?) & $\mathrm{x}$ & - & - \\
\hline Piranha & Serrasalmus brandtii (Reinhadt, 1874). & - & - & $\mathrm{x}$ \\
\hline Sabarona & Curimata elegans (Steindachner,1875). & $\mathrm{x}$ & - & - \\
\hline Traíra-cabeça-lama & Hoplias malabaricus (Bloch, 1794). & - & $\mathrm{x}$ & - \\
\hline T. cabeça- fina & Hoplias cf. lacerdae (Ribeiro, 1908). & $\mathrm{x}$ & - & - \\
\hline Tucunaré & Cichla temensis (Humboldt, 1821). & - & - & $\mathrm{x}$ \\
\hline Uiú & Hoplerythrinus unitaeniatus (Spix, 1829). & $\mathrm{x}$ & - & - \\
\hline
\end{tabular}

*peixe não coletado, identificado através de dados da literatura para a área de estudo (Santos, 2003). 
Tabela 2 . Cognição comparada relacionada com modos reprodutivos do tucunaré.

Table 2. Compared cognition related to reproductive behavior of the tucunaré species.

\section{Citação dos pecadores}

"O tucunaré, o apanhari, (...) tudo bota sentido ao ninho".

\section{Citação da literatura}

"A família Cichlidae inclui (...) peixes perciformes que põem guarda aos ovos e filhotes" (Lowe-Mcconell, 1975). "O tucunaré forra. Quando não tem um pau ou uma pedra ele alimpa "Seus ovos (tucunaré) são aderentes, sendo por esta razão postos sobre
o chão todinho e põe num lugarzinho mais duro. Aí quando está superficies de certa rigidez (...) o casal prepara, no local onde vão ser tempo de tirar ele abre aquela barroca e bota os filhos. Faz cinco, seis postos os ovos, várias covinhas, numa das quais as larvas são pelos buracos para uma só ova... Fica tudo num buraco só, mais ele abre pais colocadas quando nascem" (Santos, 1987). muita pra ir demudando de lugar".

“(...) (o tucunaré) pra tirar é no máximo 5 dias. Ele põe ali amare- "O prazo de incubação (peixes lênticos) é bem maior do que a dos linho e vai escurecendo, vai empretecendo e vai pra dentro do buraco. peixes lóticos, variando de $\mathbf{4}$ a $\mathbf{5}$ dias, até mais, às vezes " (Azevedo, Ali aquele filho vai saindo devagarzinho até ficar endurecido e deserdar 1970).

de andar com os pais".

"O peixe (tucunaré), até a posição de $200 \mathrm{~g}$ anda com os pais".

“o casal protege a prole durante várias semanas" (Junk, 1983). localmente de "inverno", que vai de maio a setembro e outra quente e úmida, denominada de "verão", que se estende de outubro a abril. A informação é consistente com os dados oficiais para o município de Lençóis (Urplan 1996) relativos, respectivamente, às menores e maiores precipitações pluviométricas e às temperaturas médias de cada mês. Diversas espécies são usadas como indicadores biológicos relacionados às variações sazonais. A proximidade da estação das chuvas, por exemplo, é reconhecida por fenômenos tais como floração de espécies, migrações e canto de pássaros e reaparecimento de espécies de peixes e répteis.

Alguns exemplos de conhecimentos locais sobre aspectos fenológicos foram organizados sob a forma de um calendário (Figura 2) que evidencia a percepção local sobre período e as ocorrências bióticas e abióticas e as atividades produtivas desenvolvidas. $\mathrm{O}$ período de estiagem tem início no mês de maio, quando o calor e as chuvas são substituídos pelo frio seco. Entre outros fenômenos relacionados a esta mudança ambiental, os pescadores mencionam o início da época de postura do cágado d'água (Phrynops sp), que deixa o rio para enterrar seus ovos em terra seca. O mês de maio também é considerado como o mais perigoso com relação a acidentes com ofídios, havendo uma crença generalizada de que nesse mês as cobras ficam "chocas" e "apuram" o veneno. Uma possível explicação para este fato seria a de que, por ocasião da estiagem, após um longo período de chuvas, esses répteis ectotérmicos, buscassem as áreas abertas para termorregulação, sendo mais facilmente encontrados em estradas e áreas antrópicas, aumentando, conseqüentemente, o número de acidentes. Entretanto não existem dados oficiais que confirmem a informação.

No mês de junho o frio acentua-se (Figura 2), sendo acompanhado por neblina nas primeiras horas da manhã. A seca, que se prolongará pelos meses subseqüentes, seria anunciada pelo canto de aves como o caboré (Glaucidium sp.), o corujão (Bubo virginianus), a zabelê (Crypturellus noctivagus) e o anu (Crotophaga ani). A associação do canto de aves a fenômenos meteorológicos (ornitoáugures meteóricos) tem sido discutida por outros autores (Brandão 1949, Marques 1998, 1999). Este último autor salienta, para um ambiente de várzea no Estado de Alagoas, que algumas aves compõem, junto com outros animais, um conjunto de "bichos que aduvinham (sic.) o tempo". Duas aves citadas neste trabalho, o caboré (Glaucidium sp.) e a zabelê (Crypturellus noctivagus), também foram citadas pelo autor referido para a várzea alagoana, sugerindo que se trata de memes amplamente distribuídos em sociedades camponesas brasileiras.

As mudanças que ocorrem na ictiofauna, associadas aos fenômenos sazonais, podem estar relacionadas tanto a características bi- ológicas das espécies (e.g., migrações com finalidades reprodutivas), quanto a respostas comportamentais a estímulos ambientais. Segundo os pescadores entrevistados, a chegada do "inverno" leva o peixe a proteger-se sob a vegetação aquática, para se "esconder do frio" ou para "dormir". Este fenômeno pode estar relacionado a uma menor taxa metabólica, associada a menor busca de alimento, o que interferiria diretamente na quantidade de pescado capturado. De acordo com os relatos, dentre as populações sujeitas a variações sazonais, a única cujo período de "reaparecimento" no rio coincide com o período de secas é a do jundiá (Rhamdia quelen); as demais "desaparecem" (tornam-se escassas e/ou de difícil captura) nesse período, "reaparecendo" somente com a "chegada das águas" (Figura 2).

No ápice da estação seca, a população muda o local e a estratégia de pesca, optando por praticá-la nas lagoas isoladas. Segundo os pescadores entrevistados é muito mais fácil capturar os peixes nessa época, devido ao espaço restrito a que ficam limitados com o baixo nível de água nas lagoas (Figura 2). Assim, embora os meses de agosto, setembro e outubro, ainda façam parte da estação fria, geralmente são meses considerados bons para a pesca. Era nesse período que outrora se realizava a pesca do "tingui", uma técnica, atualmente em desuso, que utilizava uma trepadeira como veneno. Segundo Heizer (1987), o uso de espécies vegetais como veneno de pesca é um hábito altamente arraigado na América do Sul, onde mais de uma centena de plantas já foram citadas como venenos, tendo algumas das plantas utilizadas sido domesticadas pelo homem a ponto de perderem a capacidade de reprodução espontânea. A espécie utilizada no Remanso corresponde a uma Sapindaceae (Serjania sp.), que segundo o autor referido pertence a um gênero amplamente usado no sul do Brasil.

Nos dois últimos meses de seca, inicia-se o preparo da terra, através da queima (coivara) de antigas roças ou capoeiras novas para plantio, fato este que se dará com a chegada das chuvas (Figura 2). Nesse período, incêndios nos marimbus são freqüientes. $\mathrm{O}$ fogo é consequiência de uma tentativa local, aparentemente bem sucedida, de manejar o ecossistema aquático. Segundo as informações, a cada três anos toda área de marimbus deve ser renovada para que não "apodreça". Para sua renovação, a cada ano uma parte é queimada de forma rotativa. A queima provoca renovação da vegetação hidrófila e interrompe a sucessão ecológica. Este procedimento, ainda não registrado para a região, sugere que não só a população vem sendo mantida pelo seu ambiente, mas que o contrário também pode ser verdadeiro. Justifica-se uma pesquisa mais detalhada sobre o uso do fogo e suas conseqüências no ecossistema.

A estação de chuvas e das enchentes, iniciada em outubro ou novembro, repercutiria, não só na reprodução dos peixes migratórios, 


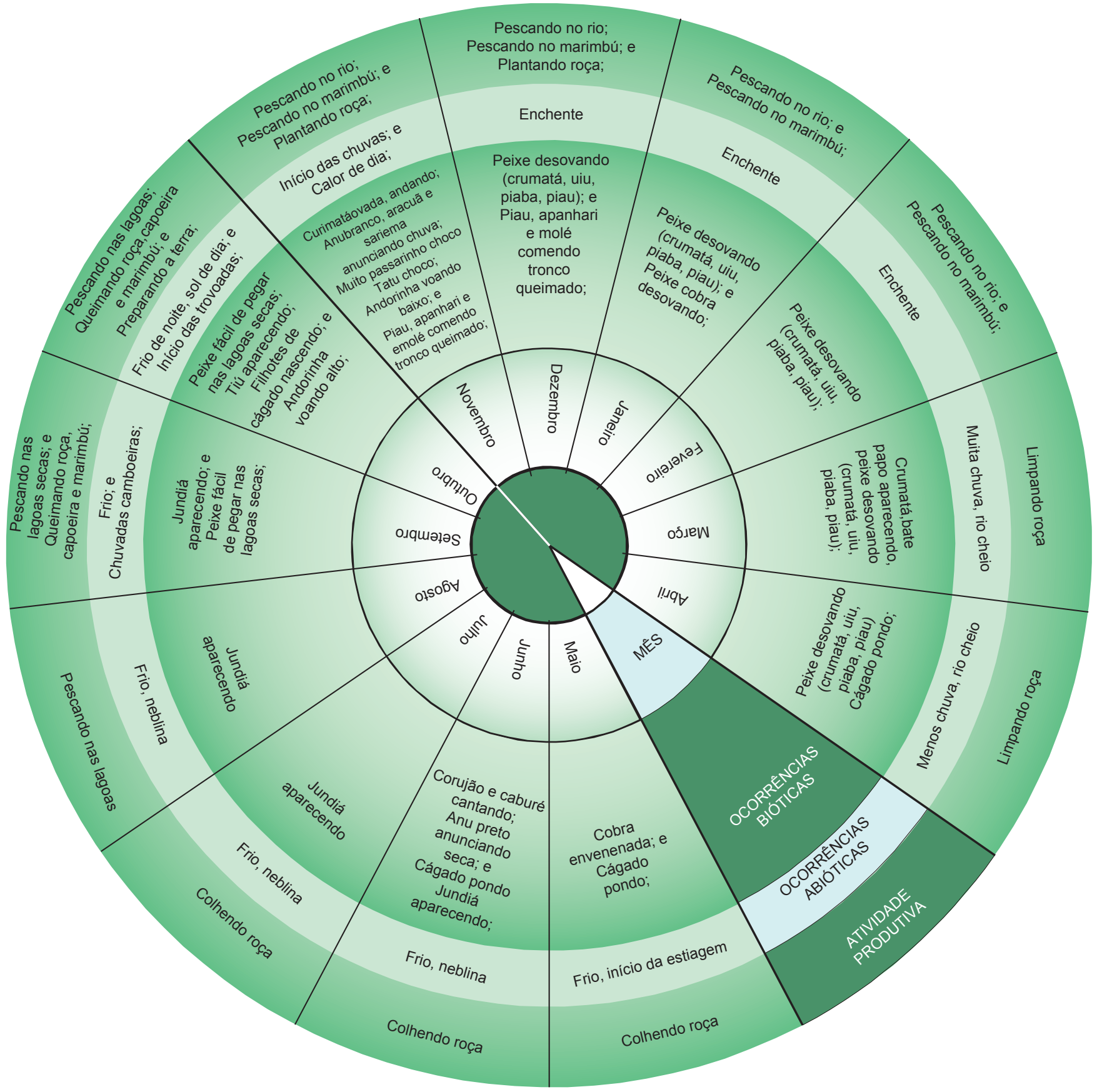

Figura 2. Calendário local relacionando o período do ano às ocorrências bióticas, abióticas e atividades produtivas.

Figure 2. Fishermen-derived local calendar relating biotic, abiotic and productive activities to the year cycle.

como também na renovação de águas e peixes das lagoas marginais que ficam isoladas no período de estiagem (Figura 2). Nessa época, segundo as informações locais, verifica-se a reprodução de peixes conhecidos por "desovarem na corrida das águas e não botarem sentido ao ninho" (uiú, crumatá, sabarona, cumbá, piau, piaba-zoião, piaba). Segundo a literatura (Von Ihering 1928, Nomura 1976, Bittencourt \& Cox-Fernandes 1990), estas espécies realizam migração no período das enchentes, desovando em águas correntes e não exibindo cuidados parentais. Para estas, conhecidas na literatura científica (Vazzoler 1996) como "espécies não guardadoras", o período reprodutivo e as variações sazonais estão intimamente relacionados. Segundo as informações locais, o uiú é o primeiro peixe que "aparece" nos períodos de enchentes (de novembro a abril), seguido de crumatás, piaus, cumbás e dois tipos de piabas. É no período de migração com finalidades reprodutivas que o rio torna-se mais piscoso, devido ao "reaparecimento" de muitos peixes.

Segundo os pescadores entrevistados, quanto ao período reprodutivo, alguns peixes são tão "certeiros" que podem ser usados como bioindicadores climáticos (para "adivinhar o tempo"). O início do período reprodutivo de algumas espécies, indicado pelo desenvolvimento gonadal, pode ser facilmente observado pelo aumento do volume do seu abdome no período imediatamente anterior à chegada das chuvas. Isto ocorre com as espécies que realizam migração com finalidades reprodutivas e não põem guarda aos ninhos (Von Ihering 
Tabela 3. Cognição comparada relacionada com modos reprodutivos para espécies não guardadoras de ovos.

Table 3. Compared cognition related to the reproductive behavior of species that do not take care of their eggs.

Citação dos pescadores

Citação da literatura

"A piaba, a crumatá, o piau e a sabarona é mais na enchente (re- "Por causa da subida dos rios elas (as águas) invadem as áreas inprodução): chega na veia d'água onde tem uma sangra fica aquelas car- undáveis, levando consigo milhares de ovos e larvas (...) naturalmente reiras delas. Ali desova pra trás. Ali perde mais do que escapa”. essa forma de reprodução inclui grandes perdas” (Junk,1983).

"A crumatá desova sempre na enchente. Que nem o tempo tá parado "A desova pode ser prejudicada por condições inadequadas no agora ela tando muito ovada acontece até que ela morre. A ova ambiente (...) se após a desova houver modificação suficiente do empedra por dentro e ela não tem como desistir". ambiente ela pode interromper-se. Então pode morrer intoxicada pela decomposição dos ovos no interior do abdome (para a carpa e truta" (Godinho, 1975).

"O piau ronca na desova. Na desova a Senhora vê o ruuuum direto.

"Algumas espécies desenvolvem nessa época (de reprodução) um músculo especial ao redor da bexiga natatória, produzindo roncos altos por causa das contrações rápidas do músculo, usando a bexiga natatória como corpo de ressonância” (Junk, 1983).

1928, Nomura 1976). Ainda de acordo com as informações locais, quando "a chuva esperada não vem" a crumatá pode morrer com as "ovas empedradas na barriga". Esta informação não encontra suporte na literatura disponível, entretanto fenômeno semelhante já foi relatado por Godinho (1975), para uma espécie de truta (Tabela 3). Outra observação local sobre a reprodução das espécies não guardadoras refere-se à baixa taxa de sobrevivência de jovens em relação às espécies guardadoras de ovos (Tabela 3 ). Uma informação sobre o piau é sustentada pela literatura científica e refere-se à produção de "roncos" no período reprodutivo (Tabela 3 ).

Assim como a estação seca, a estação das chuvas também é anunciada pelos cantos de aves que são percebidas pela capacidade de "adivinharem chuva" (ornitoáugures meteóricos). Entre eles a aracuã (Ortalis guttata ?) e a andorinha (Hirundinidae) (Figura 2). É provável que as enchentes provoquem a fertilização das águas, com benefícios para a ictiofauna, a partir da incorporação de matéria orgânica proveniente dos marimbus. Isto ocorreria tanto a partir da decomposição de folhas mortas, como do aporte de cinzas, em decorrência das queimadas.

$\mathrm{Na}$ área estudada as interações homem/ambiente são fortemente mediadas pelo conhecimento tradicional, bastante elaborado, usado para definir estratégias de apropriação dos recursos ou para o manejo dos ecossistemas.

A queima dos marimbus, de forma rotativa, apresenta-se como uma possível estratégia de manejo do ecossistema que pode ter grande repercussão no seu atual estágio de sucessão.

Ao longo do ciclo anual, diferentes pressões predatórias são exercidas pela atividade pesqueira: ora sobre as espécies lóticas (pescadas no rio, nas enchentes); ora sobre as espécies lênticas (pescadas nas "lagoas secas", no período de estiagem).

Os resultados aqui apresentados sugerem a existência de um amplo conhecimento ecológico local sobre as espécies e os ecossistemas, especialmente no que se refere à ictiofauna. $\mathrm{O}$ diálogo entre $\mathrm{o}$ conhecimento tradicional e o conhecimento científico pode contribuir para a adoção de políticas de gestão dos recursos naturais na área de estudo, considerando-se principalmente a escassez de dados científicos sobre os ecossistemas aquáticos da Chapada Diamantina.

\section{Referências Bibliográficas}

AGOSTINHO, A.A., VAZZOLER, A.E.A.M., TOMAZ, S. M. 1995. The High Paraná Basin: Limnological and Ichtyological Aspects. In Limnology in Brazil (. J.G. Tundisi, C.E.M. Bicudo \& M. Matsumara-Tundisi, eds), ABC/SBL, Rio de Janeiro, p. 56-104.

ARCHELA, R. S., GRATÃO, L.H. B. \& TROSTDORF, M. A. S. 2004. O lugar dos mapas mentais na representação do lugar. Geografia 13(1):127-141
ANDERSON, A.S. \& ANDERSON, E.S. 1983. People and Palm Forest: Biology and Utilizations of Babassu Forest in Maranhão, Brazil. Final Report to USDA Forest Service, Consortium for the Study of Man's Relationship With the Global Environment.

BALÉE, W. 1994. Biodiversidade e os Índios Amazônicos. In: Amazônia, Etnologia e História Indígena. (E.V Castro \& M.C. Cunha org.) NHII / FAPESP. p. 383-393.

BALON, E.K. 1975. Reproductive guilds of fish: a proposal and a definition. J. Fish. Res. Board Can. 13(6):821-864.

BEGOSSI, A. 2006. Métodos e análises em ecologia de pescadores. In: Dimensões humanas da biodiversidade. (I. Garay \& B. Becker, orgs). Vozes, Petrópolis. p. 299-313.

BERLIN, B. 1992. Ethnobiological classification: principles of categorizations of plants and animals in traditional societies. Princeton University Press.

BRANDÃO, T. 1949. Folclore de Alagoas. Casa Editora Ramalho, Maceió.

BITTENCOURT, M. M. \& COX-FERNANDES, C. 1990. Peixes Migradores Sustentam Pesca Comercial. Ciência Hoje. 11(64):20-24

COX, P.A. \& BALICK, M.J. 1994. The ethnobotanical approach to drug discovery. Sci. Am. 270 (66):82-87

ELISABETSKY, E. 1987. Etnofarmacologia de algumas tribos brasileiras. In: Suma Etnológica Brasileira. Vol. 1. Etnobiologia. (D. Ribeiro ed.) Vozes/Finep. Petrópolis. p. 135-148

FIGUEREDO, G.M., LEITÃO-FILHO, H. DE F. \& BEGOSSI, A. 1993. Etnobotany of Atlantic Forest coastal communities: diversity of plant uses in Gamboa (Itacucuça Island, Brazil). Hum. Ecol. 2(4):419-430.

FUNCH, R. 1997. Um guia para o visitante da Chapada Diamantina: o circuito do diamante. Coleção Apoio, $n^{\circ} 15$. Salvador: Empresa Gráfica da Bahia.

GODINHO, H.M. 1975. Considerações Gerais Sobre Anatomia dos Peixes. Poluição e Piscicultura. CIBPU. São Paulo.

HAYS, T.E. 1976. An empirical method for the identification of covert categories in ethnobiology. Am. Ethnol. 3:489-507

HEIZER, R.F. 1987. Venenos de Pesca. In: Suma Etnológica Brasileira. Vol. 1. Etnobiologia. (D. Ribeiro, ed.). Vozes/Finep. Petrópolis. p. 189-233

HANAZAKI, 2003. Comunidades, conservação e manejo: o papel do conhecimento ecológico local. Biotemas, Florianópolis, 16(1):23-47.

JEMPSEN, D.B., WINEMILLER, K.O., \& TAPHORN, D.C. 1997. Temporal patterns of resource partioning among Cichla species in venezuelan blackwater river. J. fish biol., 51:1085-1108.

JENSEN, A.A. 1985. Sistemas indígenas de classificação de aves: aspectos comparativos, ecológicos e evolutivos. Tese de Doutorado, Universidade Estadual de Campinas, Campinas. 
JUNK, W.J. 1983. A Ictiofauna da Região Amazônica. In: Amazônia: Desenvolvimento, Integração e Ecologia. (E. Salati, W. J. Junk, E.O.R. Shubart \& A. E. Oliveira, eds) Editora Brasiliense. Brasília. p. 45-100.

LÉVI-STRAUSS, 1987. O uso de plantas silvestres na América do Sul tropical. In: Suma Etnológica Brasileira. Vol. 1. Etnobiologia. (D. Ribeiro, ed.). Vozes/Finep. Petrópolis. p. 91-94.

LIMA, C.C.U. DE \& NOLASCO, M.C. 1997. Lençóis: uma ponte entre a geologia e o homem. UEFS. Feira de Santana, Bahia.

LOWE-MCCONNELL, R.H. 1987. Ecological Studies in Tropical Fish Communities. Cambridge University Press.

MARQUES, J.G.W. 1991. Aspectos ecológicos na etnoictiologia dos pescadores do complexo estuarino-lagunar Mundaú-Manguaba, Alagoas. Tese de Doutorado.Universidade Estadual de Campinas, Campinas.

MARQUES, J. G. W. 1995. Pescando pescadores: etnoecologia abrangente no Baixo São Francisco alagoano. NUPAUB, Universidade de São Paulo. São Paulo

MARQUES, J.G.W. 1998. Do canto bonito ao berro do bode: percepção do comportamento de vocalização em aves entre camponeses alagoanos. Rev. Bras. Etologia, ( $n^{\circ}$ especial) 71-85.

MARQUES, J.G.W. 1999. Da gargalhada ao pranto. Inserção Etnoecológica da Vocalização de Aves em Ecossistemas Rurais do Brasil. Tese Professor Titular. Universidade Estadual de Feira de Santana. Feira de Santana.

MORIN-LABATUT, G. \& AKATAR, S. 1992. Traditional Knowledge: a resource to manage and share. Development 4:24-30.

MOURÃO. J.S. \& NORDI, N, 2002. Comparação entre as taxonomia folk e científica para peixes do estuário do Rio Mamanguape, Paraíba, Brasil. Interciência, 27:664-668.

MONTENEGRO, S.C.S. 2002. A conexão Homem/Camarão (Macrobrachium carcinus e $M$. acanthurus) no Baixo São Francisco Alagoano: uma abordagem etnoecológica. Tese de Doutorado. Universidade Federal de São Carlos.

NOMURA, H. 1976. Ictiologia e Piscicultura. Nobel, São Paulo, SP.

OLIVEIRA F. O. \& WERBA, G. C. 1999. Representações Sociais In: Psicologia Social Contemporânea. (M. da G. C. Jacques \& M. N. Strey, org.), $3^{\mathrm{a}}$ ed. Vozes, Petrópolis.

OVERAL, W.L. POSEY, D.A., 1996. Práticas agrárias dos índios Kayapó do Pará: subsídios para o desenvolvimento da Amazônia. In: Uma estratégia Latino-Americana para a Amazônia. (C. Pavan \& M.C. Araújo, eds.). Memorial. São Paulo.
POSEY, D.A., 1983. Indigenous knowledge and development: an ideological bridge to the future. Ciência e Cultura, 35(7):18-24.

POSEY, D.A.. Etnoecology as applied anthropology in Amazonian development. Hum. Organ. 43(2):95-107, 1984.

POSEY, D.A. 1987. Etnobiologia, teoria e pratica. In: Suma Etnológica Brasileira. Vol. 1. Etnobiologia. (D. Ribeiro, ed.). Vozes/Finep. Petrópolis. p.15-25.

RANTIN, T.F., GLASS, M.G., KALININ, A.L., VERZOLA, R.M.M. \& FERNANDES, M.N. 1993. Cardio-respiratory responses in tow ecologically distinct erythrinids (Hoplias malabaricus and H. lacerdae) exposed to graded enviromental hipoxia. Enviromental biology of fish. Canadá. 36:93-97,

RIBEIRO, B, 1987. Chuvas e constelações: calendário econômico dos índios Desâna. Ciência Hoje 36(6):14-23.

SANTOS, A.C.A. 2003. Caracterização da ictiofauna do alto rio Paraguaçu, com ênfase nos rios Santo Antônio e São José, Chapada Diamantina, Bahia. Tese de Doutoramento. UFRJ/ Museu Nacional. Rio de Janeiro.

SANTOS, E. 1987. Peixes de Água Doce. (Vida e Costumes dos Peixes do Brasil). $4^{\mathrm{a}}$ ed., Itatiaia, Belo Horizonte.

SILVA, V. A, 1997. Etnobotânica dos índios Xucurú, com ênfase nas espécies do Brejo da Serra do Ourorubá (Pesqueira, Pernambuco). Dissertação de Mestrado. Universidade Federal de Pernambuco. Recife.

SOUTO, F. J. B. 2007. Uma abordagem etnoecológica da pesca do caranguejo, Ucides cordatus, Linnaeus, 1763 (Decapoda: Brachyura), no manguezal do Distrito de Acupe (Santo Amaro-BA). Biotemas. 20(1):69-80.

SPRADLEY, J. P. \& MCCURDY, D.W. 1972. The cultural experience: ethnography in complex society. Tennessee, Kingsport Press of Kingsport.

URPLAN, 1996. Área de Proteção Ambiental Marimbus-Iraquara: diagnóstico do meio físico, biótico e sócio econômico. Governo do Estado da Bahia, SECULT/ Coordenadoria de desenvolvimento e turismo.

VAZZOLER, A.E.A. de M. 1996. Biologia da Reprodução de Peixes Teleósteos: Teoria e Prática. Maringá, EDUEM, São Paulo, SP.

VON IHERING, R. 1928. Os Óvulos e a Desova dos Peixes D’água Doce no Brasil. Boletim Biológico, Laboratório de Parasitologia da Faculdade de Medicina de São Paulo, fascículo. 14. São Paulo, SP

WERNER, O \& J. FENTON. 1973. Method and theory in ethnoscience or ethnoepistemology. Columbia University Press, New York. 